\title{
Metodologia da problematização - Aplicabilidades no ensino de enfermagem
}

\section{fundamental}

\author{
Methodology of problematization - Applicability in the teaching of fundamental nursing \\ Metodologia da problematização - Aplicabilidades no ensino de enfermagem fundamental
}

Recebido: 23/04/2021 | Revisado: 01/05/2021 | Aceito: 14/05/2021 | Publicado: 22/05/2021

\author{
Daiana Moreira Gomes \\ ORCID: https://orcid.org/0000-0001-9387-0619 \\ Associação Brasileira de Enfermeiros Cientistas, Brasil \\ E-mail: daigomes_87@hotmail.com \\ Victor Hugo de Paula Flauzino \\ ORCID: https://orcid.org/0000-0001-5156-0030 \\ Faculdade Unyleya, Brasil \\ E-mail: prof.victorflauzino@unyleya.edu.br \\ Priscila Gramata da Silva Vitorino \\ ORCID: https://orcid.org/0000-0002-1201-6945 \\ Associação Brasileira de Enfermeiros Cientistas, Brasil \\ E-mail: prigramaenf@yahoo.com.br \\ Luana de Oliveira Hernandes \\ ORCID: https://orcid.org/0000-0001-8828-7146 \\ Associação Brasileira de Enfermeiros Cientistas, Brasil \\ E-mail: luanaoliveira2306@gmail.com \\ Gisella de Carvalho Queluci \\ ORCID: https://orcid.org/0000-0003-0496-8513 \\ Departamento de Enfermagem Fundamental EEAP/UNIRIO \\ E-mail: gisella.queluci@unirio.br \\ Jonas Magno dos Santos Cesário \\ ORCID: https://orcid.org/0000-0003-1785-3555 \\ Faculdade Unyleya, Brasil \\ E-mail: prof.jonasmagno@unyleya.edu.br
}

\begin{abstract}
Resumo
As metodologias ativas surgiram com o processo de transformação da educação, enquanto ferramentas de ensino modificam a educação tradicional, que é voltada para um aprendizado linear e limitado, para um aprendizado mais crítico e reflexivo, o que torna o discente provedor de sua própria aprendizagem. Este estudo avaliou a aplicação da metodologia da problematização no ensino teórico-prático da disciplina de fundamentos de enfermagem II de uma universidade do Rio de Janeiro, por meio de uma abordagem qualitativa, onde os participantes do estudo foram os discentes e docentes da mesma disciplina. Os dados coletados inicialmente no ano de 2014, foram comparados com estudos atuais. Mesmo com o passar dos anos, outras pesquisas recentes também relatam problemas como a resistência dos professores, falta de preparo docente, ausência de interesse dos discentes e infraestrutura inadequada da instituição de ensino superior. No que se refere especificamente a respeito da estrutura curricular do curso de enfermagem, foi possível constatar que existe uma necessidade de aprimorar as metodologias, de forma que envolvam a formação do discente para a prática assistencial e que ensinem o futuro profissional a consumir e produzir ciência. Os próximos anos exigirão cada vez mais a utilização de novas práticas, adaptadas às transformações de um mundo cada vez mais conectado. A elaboração de estudos que mantenham os docentes a par da necessidade da implantação de métodos de ensino inovadores é fundamental e viabiliza o aprimoramento do cuidado, forma profissionais mais capacitados, contribui para o desenvolvimento da ciência da enfermagem e permite novas experiências.
\end{abstract}

Palavras-chave: Educação em enfermagem; Metodologia da problematização; Metodologias ativas; Ensino.

\begin{abstract}
This research aims to evaluate the application of the methodology of problematization in the theoretical and practical teaching of Nursing Fundamentals II. This is a descriptive study with a qualitative approach, having as study participants the students enrolled in the discipline of Nursing Fundamentals of the Aurora de Afonso Costa Nursing School - EEAAC/UFF, in the 2nd semester of 2014 and the teachers of this same discipline. Hybrid content analysis was performed. After data analysis, these were divided into three categories: teacher education and didactics applied in higher education; the curriculum of the nursing course: fundamental skills for the professional training of the future nurse; the use of them etiologic of problematization in higher education, to discuss about possible changes and how they would be carried out, taking into account professional competencies, the
\end{abstract}


importance of the relationship between nurse and patient and nursing practices as whole, through the training of students with more power of reflection, criticism and technical capacity. The new methodological approach of problematization allowed the student to clearly understand the competencies of the nurse and how they can be used in their professional routine. This methodological application served as a substantial method to be applied in the discipline, and the teacher can expand the content and work on issues related to problematization nursing care and professional education. Despite all the changes already underway, the methodology of problematization still represents a challenge nowadays of higher education.

Keywords: Nursing education; Methodology of problematization; Active methodologies; Teaching.

\begin{abstract}
Resumen
Esta investigación tiene como objetivo evaluar la aplicación de la metodología de problemática en la enseñanza teórica y práctica Fundamentos de Enfermería II. Se trata de un estudio descriptivo con un enfoque cualitativo, teniendo como participantes de estudio a los alumnos matriculados en la disciplina de Fundamentos de Enfermería de la Escuela de Enfermería Aurora de Afonso Costa - EEAAC/UFF, en el $2^{\circ}$ semestre de 2014 y a los profesores de esta misma disciplina. Se realizó un análisis de contenido híbrido. Después del análisis de datos, estos se dividieron en tres categorías: educación del maestro y didáctica aplicada en la educación superior; el currículo del curso de enfermería: habilidades fundamentales para la formación profesional de la futura enfermera; el uso de la metodología de problematización en la educación superior, para discutir sobre posibles cambios y cómo se llevarían a cabo, teniendo en cuenta las competencias profesionales, la importancia de la relación entre las prácticas de enfermería y paciente y enfermería en su conjunto, a través de la formación de estudiantes con más poder de reflexión, crítica y capacidad técnica. El nuevo enfoque metodológico de la problematización permitió al estudiante entender claramente las competencias de la enfermera y cómo se pueden utilizar en su rutina profesional. Esta aplicación metodológica sirvió como un método sustancial a aplicar en la disciplina, y el maestro puede ampliar el contenido y trabajar en cuestiones relacionadas con la atención de enfermería y la educación profesional. A pesar de todos los cambios ya en marcha, la metodología de la problematización sigue representando un desafío hoy en día en la educación superior.
\end{abstract}

Palabras clave: Educación en enfermería; Metodología de problematización; Metodologías activas; Enseñanza.

\title{
1. Introdução
}

É possível observar que o sistema educacional, principalmente relacionado à Enfermagem, passou por grandes transformações, com o objetivo de buscar uma melhoria e/ou aperfeiçoamento do ensino-aprendizagem. Entretanto, mais do que resolver, a ideia de mudança implica numa questão desafiadora, a necessidade de inovações educacionais, ajustes curriculares e inovações pragmáticas, para poder acompanhar as modificações que ascendem no mundo contemporâneo (Fini, 2018).

Com o instituto de compreender a situação-problema do paciente, o trabalho da enfermagem também busca estimular a consciência crítica, tanto do profissional quanto de estudantes. Com isso, ao basear-se na melhoria assistencial de enfermagem, a aplicabilidade de diferentes métodos de ensino-aprendizagem na vivência da prática hospitalar, têm o poder de formar profissionais que estarão preparados e familiarizados com problemas reais e, faz desses profissionais, diferenciais para um mercado tão exigente (Duarte et al., 2019).

A explicação ligada à abordagem do paciente através da compreensão de situações-problema na prática de enfermagem é imprescindível, uma vez que isto está diretamente relacionado a um tipo de metodologia ativa chamada metodologia da problematização, a qual é uma ferramenta inovadora que mantém o discente preparado para atuar como ser social, ativo, reflexivo, criativo e prestativo, com habilidades como a compreensão e modificação da sua realidade (Rios \& Caputo, 2019).

As metodologias ativas surgiram com o processo de transformação da educação, enquanto ferramentas de ensino modificam a educação tradicional, que é voltada para um aprendizado linear e limitado, para um aprendizado mais crítico e reflexivo, o que torna o discente provedor de sua própria aprendizagem. Dentre as propostas de metodologias ativas, algumas escolas têm trabalhado em seu currículo com a Aprendizagem baseada em Problemas (ABP) e a Metodologia da Problematização. Propostas distintas que trabalham de forma equalitária com problemas relacionados ao desenvolvimento do processo de ensino-aprendizagem (Duminelli et al., 2019). 
$\mathrm{Na} \mathrm{ABP}$, o incentivo aos discentes reunidos em pequenos grupos a usar seus conhecimentos anteriores para resolver certos problemas na pesquisa, têm o objetivo de desenvolver o raciocínio crítico, habilidades de comunicação e compreensão da aprendizagem ao longo da vida. Na metodologia da problemática, por meio da observação, o problema é retirado da realidade vivida pelos discentes. (Berbel., 2011).

A proposta problematizadora surge com o objetivo de formar discentes cada vez mais capacitados e com pensamento crítico da realidade e dos problemas. A transformação da realidade é objetivo principal desse método, através da observação e da elaboração de estratégias para a intervenção na realidade. Cada tipo de grupo vai definir um tipo de atuação possível e um grau diferente de intervenção na realidade (Berbel, 2011). Portanto, a realidade observada irá nortear quais os tipos de transformações ali necessárias.

A problematização possibilita que o professor seja um facilitador para o discente estar sempre ativo, ao elaborar propostas, expor seus questionamentos e ideias, através da observação do seu dia a dia, ou seja, da realidade vivida pelo discente e, que através de sua observação, ele seja motivado a perceber e identificar os problemas, para, assim, buscar estratégias de resolução deles. (Mata et al., 2017).

No ensino superior brasileiro, os trabalhos de Maguerez, Bordenave e Pereira, na década 1980, podem ser considerados referência na utilização dessa metodologia. O problema é extraído a partir da observação da realidade, baseado no Arco de Charles Maguerez, o qual possui cinco etapas, conforme ilustrado na Figura 1 e o discente seguirá métodos para alcançar o resultado desejado (Mattar \& Aguiar, 2018).

Figura 1. Arco de Charles Maguerez.

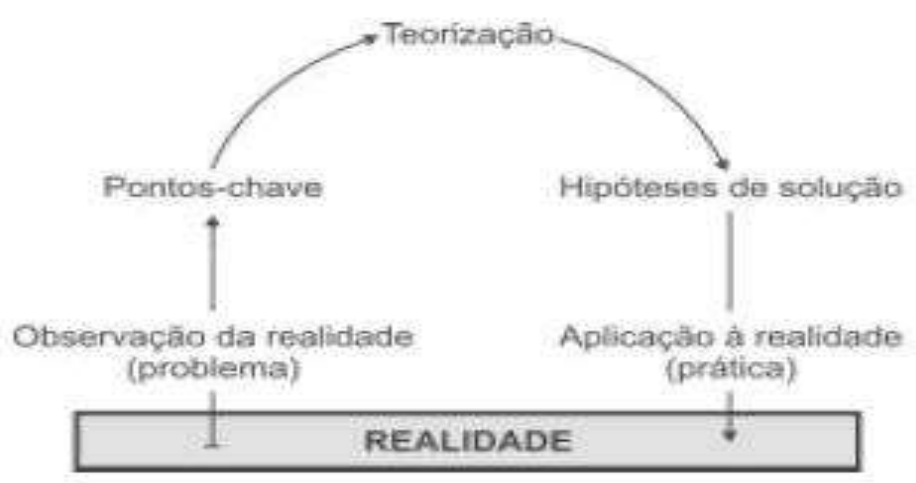

Fonte: Bordenave e Pereira (2004).

Na primeira etapa do Arco de Charles Maguerez, o discente analisa que tipo de necessidade está mais evidente, através da observação da realidade, para buscar identificar o verdadeiro problema a ser trabalhado para transformá-lo e resolvê-lo. A observação é o período em que o discente irá problematizar a realidade, ao apontar o que está de errado, onde precisa melhorar, ou seja, o que precisa ser extraído dessa realidade para que haja uma mudança (Cortes, Padoin \& Berbel, 2018).

No momento em que o problema é detectado, o discente começa a elaborar pontos-chave que envolvem esse problema, como por exemplo, questões que envolvem a vivência, como questões sociais, culturais, educação e saúde. Esses pontos-chave direcionam o discente para se aprofundar em uma investigação mais detalhada do problema, norteiam o discente no que será estudado e pesquisado sobre as questões levantadas na observação. Esse é o momento em que o discente percebe que a maioria dos problemas, independente de qual seja, são multicausais.

A pesquisa propriamente dita é feita na teorização, que é caracterizada como o momento em que os discentes iniciam a percepção do problema e questionar o motivo dos acontecimentos observados nas fases anteriores (Mattar \& Aguiar, 2018). 
Etapa essa onde é feita a investigação através do uso de livros, revistas, artigos, internet e outros, para a busca de informações apropriadas ao tema escolhido.

A quarta etapa do Arco de Charles Manguerez consiste na confecção de alternativas viáveis para resolver os problemas visualizados, de forma crítica e criativa, que confronta teoria e realidade, ou seja, os discentes formulam hipóteses de solução. Na quinta etapa do Arco, aplicação à realidade, os personagens em questão são motivados à construção de novos conhecimentos para modificar a realidade observada, por meio das suposições anteriormente planejadas (Alves et al., 2017).

A problematização possibilita, através do olhar crítico da realidade, uma modificação das práticas pessoal, profissional e social do sujeito (Cortes, Padoin \& Berbel, 2018). Assim, a metodologia da problematização se encaixa no desenvolvimento de estratégias de ensino em qualquer ambiente social, a partir do momento que exija do discente além do conhecimento, tomadas de decisões as quais venham intervir nos problemas da realidade onde esse discente está inserido, isso exige uma maior responsabilidade do mesmo, como já salientava Berbel (2011).

$\mathrm{O}$ enfermeiro exerce atividades fundamentais para o desenvolvimento da assistência prestada ao paciente e para seu próprio conhecimento, como o cuidado, a gerência, a educação e a pesquisa. Portanto, as atividades desse profissional passam pela compreensão da dinâmica do cuidar ao gerenciar, educar e pesquisar (Sulzbacher et al., 2017). Porém, para realizar essas funções, ele tem que possuir habilidade técnica, conhecimento científico e ao mesmo tempo interagir com o pensamento crítico e reflexivo de forma que colabore com a assistência do paciente de maneira objetiva e resolutiva.

As capacidades de pensamento crítico e raciocínio clínico para identificar as condições de saúde e de doença das pessoas são suscetíveis ao aprendizado e aprimoramento. Para isso, a aprendizagem precisa ser considerada um sistema contínuo e dinâmico que exige do enfermeiro a conquista de novos conhecimentos, ao aprimorar suas habilidades de pensar, de resolução de problemas e de fazer julgamentos. Isso deixa o enfermeiro pronto para fazer suposições, mostrar ideias e validar suas conclusões (Oliveira, Pereira \& Castro, 2018).

A enfermagem fundamental, como disciplina, é a responsável por inserir o discente no ambiente hospitalar. Por esse motivo, é de grande relevância o contato desse discente de enfermagem com a realidade, isso faz com que ele pense criticamente sobre a assistência prestada em sua própria vivência para assim poder aplicá-la em sua prática, o que requer competência técnica, conhecimento e atitude. Vale ressaltar que esses pontos são potencialmente trabalhados no ensino tradicional, porém, mesmo assim, este tipo de ensino deixa lacunas na aprendizagem, o que torna indispensável a utilização de metodologias ativas para complementar a formação (Silva et al., 2020).

Com base nisso, traçou-se como objetivo avaliar a aplicação da metodologia da problematização no ensino teóricoprático da disciplina de fundamentos de enfermagem II de uma universidade do Rio de Janeiro.

\section{Metodologia}

Trata-se de um estudo descritivo com abordagem qualitativa, conforme Cesário, Flauzino e Mejia (2020) este tipo de pesquisa não há forma numérica, pois o pesquisador utiliza uma forma indutiva para descrever a situação observada. A aplicação do método da problematização ocorreu nos momentos de Ensino Teórico Prático (ETP), no laboratório de Fundamentos de Enfermagem da Escola de Enfermagem Aurora de Afonso Costa da Universidade Federal Fluminense (EEAAC/UFF). Após aprovação do projeto pelo comitê de ética e pesquisa da Universidade Federal Fluminense, foram conduzidas entrevistas qualitativas com 9 (nove) discentes inscritos na disciplina de Fundamentos da EEAAC/UFF, no $2^{\circ}$ semestre de 2014 e 6 (seis) docentes desta mesma disciplina. O quantitativo de sujeitos foi definido por uma amostragem de conveniência. 
Os critérios de inclusão foram: discentes e professores que assinaram o Termo de Consentimento Livre e Esclarecido (TCLE). Como critério de exclusão: para os discentes, aqueles não matriculados regularmente na disciplina e, para os professores, aqueles que estavam de férias.

A coleta de dados, com os discentes, ocorreu em dois encontros realizados com todo o grupo que aceitou fazer parte da pesquisa. O grupo se reuniu com o pesquisador, conforme a disponibilidade dos mesmos após suas atividades acadêmicas, para conhecer o projeto, entrega do TCLE e agendamento das datas dos encontros dos que confirmaram participar do estudo. Em relação aos docentes, ocorreu através da realização de entrevistas junto ao pesquisador e através do envio da mesma pelo correio eletrônico para os docentes que não puderam, por motivo de indisponibilidade de horário, marcar a entrevista. Para a análise dos dados coletados foi realizada uma análise de conteúdo híbrida.

Para a discussão dos resultados e compreensão da possível relevância atual do tema, foram selecionados recentes e publicados nos últimos 3 (três) anos no Google Acadêmico, com os descritores em ciências da saúde (DeCS): Educação em enfermagem; Metodologia da problematização; Metodologias ativas e Ensino, e que contribuíssem para responder ao objetivo central deste estudo.

\section{Resultados}

No primeiro encontro com os estudantes de enfermagem, sugeriu-se o levantamento de problemas vivenciados no ensino teórico-prático e que tivessem a ver com a Enfermagem e a disciplina de Fundamentos de Enfermagem. A partir daí, no Quadro 1 abaixo foram destacados alguns pontos-chave e estes aparecem na ordem em que emergiram durante a discussão sobre o problema identificado intitulado: o (des)preparo e estratégias docentes para o ensino teórico e prático de enfermagem.

Quadro 1. Pontos-chave do problema principal identificado pelo grupo de discentes.

\begin{tabular}{|c|l|}
\hline Ordem & \multicolumn{1}{|c|}{ Elementos destacados } \\
\hline $\mathbf{1}$ & Desorganização da equipe docente \\
\hline $\mathbf{2}$ & Quantitativo de aulas não favorece o aprendizado \\
\hline $\mathbf{3}$ & Falta de comunicação entre docente-discente \\
\hline $\mathbf{4}$ & Tempo para estudar \\
\hline $\mathbf{5}$ & Quantitativo grande de discentes \\
\hline $\mathbf{6}$ & Currículo não adequado ao aprendizado \\
\hline
\end{tabular}

Fonte: Autores (2021).

De acordo com o Quadro 1 observamos que os estudantes questionaram a organização da disciplina. Além disso, o quantitativo de discentes por turma dificulta o processo de ensino-aprendizagem, uma vez que o professor não consegue dar a mesma atenção a todos os discentes.

A comunicação foi um ponto destacado, também, por muitos discentes. Para eles, alguns docentes ainda assumem, às vezes, uma postura autoritária diante de questionamentos. Tal comportamento faz com que os discentes fiquem retraídos ou desconfortáveis para questionar atitudes ou procedimentos em certas situações de enfermagem.

O tempo para a organização do estudo parece ser complicado para os estudantes, e talvez, muitos ainda necessitam de certa maturidade para desenvolver competências e uma autonomia para atingir os objetivos da disciplina. Na verdade, a organização curricular do curso de Enfermagem precisa, indubitavelmente, de uma discussão mais ampliada conforme as competências que se espera do perfil profissional dos enfermeiros.

Após a listagem dos problemas, os estudantes tiveram 07 dias para buscarem leituras de artigos e outros acervos acerca do tema para compreender a causa desses problemas presentes no meio acadêmico e que interferem no processo ensinoaprendizagem. A partir das falas e registros no segundo encontro, destacou-se no Quadro 2, a síntese dos problemas encontrados na disciplina, na ordem em que eles aparecem: 
Quadro 2. Síntese do conteúdo das falas e registros.

\begin{tabular}{|c|l|}
\hline Ordem & \multicolumn{1}{|c|}{ Elementos destacados } \\
\hline $\mathbf{1}$ & Didática \\
\hline $\mathbf{2}$ & Atitude docente \\
\hline $\mathbf{3}$ & Conhecimento docente e discente das diretrizes curriculares \\
\hline $\mathbf{4}$ & Falta de preparo docente \\
\hline $\mathbf{5}$ & Necessidades de novas metodologias \\
\hline $\mathbf{6}$ & Importância do conhecimento sobre currículo e do projeto pedagógico da instituição \\
\hline $\mathbf{7}$ & Desmotivação no processo ensino-aprendizagem \\
\hline $\mathbf{8}$ & Falta de interação docente-discente \\
\hline
\end{tabular}

Fonte: Autores (2021).

Para complementar o entendimento e, na tentativa de entender a metodologia de ensino utilizada no ensino superior e os significados acerca do uso de processos ativos pelos docentes, foi realizada a análise de conteúdo das falas dos mesmo após a entrevista. Observaram-se semelhanças com alguns pontos destacados pelos estudantes. O Quadro 3 mostra significados das falas dos docentes, na ordem que apareceram durante as entrevistas:

Quadro 3. Significado das falas dos docentes de enfermagem.

\begin{tabular}{|c|l|}
\hline Ordem & \multicolumn{1}{|c|}{ Elementos destacados } \\
\hline $\mathbf{1}$ & Professor não aceita desafios \\
\hline $\mathbf{2}$ & Mudança na prática educativa pelos docentes \\
\hline $\mathbf{3}$ & Necessidade de formar enfermeiros para cuidar e não só para a pesquisa \\
\hline $\mathbf{4}$ & A importância de trabalhar situações na prática \\
\hline $\mathbf{5}$ & Precariedade de recursos \\
\hline $\mathbf{6}$ & Atualizar conteúdos \\
\hline $\mathbf{7}$ & Docentes querem deter conhecimento \\
\hline $\mathbf{8}$ & Discentes devem assumir papel ativo em sala de aula \\
\hline $\mathbf{9}$ & Professor que quer mudar passa por dificuldades \\
\hline $\mathbf{1 0}$ & Rever métodos de ensino \\
\hline $\mathbf{1 1}$ & Há necessidade de mesclar o método de ensino tradicional e ativo \\
\hline
\end{tabular}

Fonte: Autores (2021).

O Quadro 3 destaca os principais significados das falas dos docentes, onde eles questionam a necessidade de atualizar o os objetos de estudo em sala de aula, assim como a prática educativa. Um dos pontos questionados pelos docentes, também foi a atitude de outros professores em sala de aula ao querer deter o conhecimento, pois não permitem a participação ativa do discente do seu processo de ensino-aprendizagem. Para alguns professores é importante que o discente tenha um papel ativo em sala de aula, porém a importância do professor é fundamental para mostrar o caminho ao discente e instruir esse discente durante seu processo de formação educacional.

Os docentes falaram da importância de implantar um método ativo de ensino em sala de aula e de mesclar os métodos de ensino - o tradicional e o ativo - para poder alcançar todos os tipos de perfis de discentes. Porém, questionaram a falta de recursos materiais que eles enfrentam ao querer elaborar uma aula mais dinâmica, por falta de suporte técnico, disponibilidade de salas, tempo ou até mesmo a falta de interesse dos próprios discentes em levar a nova forma de ensino a sério.

A necessidade de formar enfermeiros para cuidar também foi um ponto destacado na fala dos docentes, pois há uma preocupação com o processo educativo desses futuros profissionais dentro das instituições de ensino, onde alguns professores direcionam o discente para a parte da pesquisa, o que deixa um pouco de lado o principal papel do enfermeiro que é a sua relação com o paciente no campo de prática. 
A partir dos quadros citados e dos significados listados, elaboramos três categorias para análise, a formação docente e a didática aplicada no ensino superior; o currículo do curso de enfermagem: competências necessárias à formação profissional do futuro enfermeiro e o uso da metodologia da problematização no ensino superior.

\section{Discussão}

\section{A formação docente e a didática aplicada no ensino superior}

A forma de ensinar se dá através da didática, onde o professor irá nortear o aprendizado desse discente através de métodos e técnicas adequados. A capacitação dos docentes e a elaboração de uma didática adequada e substancial é necessária para auxiliar no desenvolvimento de um discente mais crítico e reflexivo, capaz de despertar esse discente para novos conhecimentos (Silva et al., 2020).

Porém, para que haja essa comunicação e didática adequada é necessário também que o próprio discente se interesse pelos novos métodos apresentados pelos docentes em sala de aula, para renovar o modelo de ensino tradicional. A grande limitação para a mudança da didática na visão de alguns docentes é o desinteresse do próprio discente em se ajustar a um novo método de ensino mais ativo e dinâmico. A docente B afirma que:

A principal limitação são os próprios discentes. Muitas vezes eles falam que o professor que faz isso, não quer dar aula. Se você leva um texto para eles estudarem, falam que o professor não quer dar aula. (...) Alguns colegas também professores são resistentes a esses tipos de métodos, fala também que é blá blá blá, que é bate papo com discente (docente B). ${ }^{1}$

Por esse motivo, a falta de interesse dos discentes a se adaptarem com novas formas de didáticas podem fazer com que o docente se limite a apresentar novos métodos de ensino e assim se torne repetitivo ao preferir a utilização de um modelo tradicional de ensino.

Muitos professores têm dificuldades de elaborar uma didática adequada para desenvolver as atividades planejadas e que consiga a atenção dos discentes. A falta de didática e o despreparo dos professores, podem ser oriundos da prática de uma educação com caráter fragmentário, na qual as atividades didáticas não se integram como se elas não tivessem relação umas com as outras, o que gera uma falta de integração de conteúdos de diversos componentes curriculares (Penof, Leonardo \& Farina, 2020).

Para o docente $\mathrm{C}$, a falta de didática também pode ser oriunda da própria falta de espaço de alguns professores para um novo método, por medo da exposição ou até mesmo por querer deter o conhecimento e ele relata que:

Porque muitos dos nossos colegas pensam que na sala de aula eles detêm o conhecimento e eles querem passar o conhecimento, pensam que vão se expor, e não querem utilizar uma metodologia diferente (docente C). ${ }^{2}$

Por outro lado, a relação docente-discente é vista, por alguns docentes ou até mesmo discentes, como meramente profissional, o que dificulta, portanto, uma maior abertura e aceitação de críticas e novas ideias para aulas. O Discente 9 relata que:

Há um "pequeno espaço para retornos" tanto dos discentes quanto dos docentes (discente 9). ${ }^{3}$

\footnotetext{
${ }^{1}$ A entrevista qualitiva, do docente $\mathrm{B}$, foi realizada por Daiana Moreira Gomes

${ }^{2}$ A entrevista qualitiva, do docente $\mathrm{C}$, foi realizada por Daiana Moreira Gomes
} 
É importante que o professor saiba estabelecer um relacionamento com o discente, que ocorra um aprendizado mútuo, para que o docente consiga, através desse relacionamento docente-discente, trilhar pela didática certa e inovadora, com métodos atuais que auxiliem na formação de profissionais mais críticos e autônomos.

Muitas instituições se preocupam mais com a competência e os títulos adquiridos pelo profissional na área de formação, não exige a formação desse profissional no ramo da educação. Com isto infelizmente, não são levadas em consideração as perspectivas e experiências como professor e não há uma avaliação de prática pedagógica na seleção de professores (Medeiros, Valente \& Marin, 2018).

Entretanto para que o docente possa apresentar um novo método de ensino se faz necessário que ele tenha um método para aplicar os novos métodos e isso se dá através da inovação de sua própria didática como uma transformação da prática educativa. Aprimorar o papel de professor contribui significativamente para a formação do profissional de nível superior, especialmente se levar em consideração a dinâmica da sociedade imediatista em que vivemos (Miranda, 2017).

Para isso, torna-se urgente romper com a lógica da fragmentação dos conteúdos de ensino, através de uma integração interdisciplinar, o potencial crítico e reflexivo dos sujeitos envolvidos nos processos de ensino-aprendizagem (Fernandes, Freitas, \& Carneiro, 2019).

\section{O currículo do curso de enfermagem: competências necessárias à formação profissional do futuro enfermeiro}

A Lei de Diretrizes e Bases da Educação (LDB) n ${ }^{\circ}$ 9.394/96 aborda no capítulo IV, a sua finalidade que, dentre outras, é formar diplomados nas diferentes áreas de conhecimento, aptos para serem inseridos em ramos profissionais e para a colaboração no desenvolvimento da sociedade brasileira, o que contribui para sua formação contínua (Lei n 9394, 1996).

Porém, o docente D relata que as práticas de educação utilizadas no ensino superior precisam mudar. Ele questiona até que ponto é válido o discente fazer fichamentos, resenhas e ler artigos sem uma fundamentação e direcionamento para isso. Para ele:

O professor não tem que jogar um monte de artigo para o discente ler e ir para a sala de aula discutir artigo, pois o discente não tem maturidade pra isso. Isso acontece em muitas disciplinas (docente $D$ ). ${ }^{4}$

Logo, nota-se que o ideal é ter uma reorganização, já que Ferraz, Ferreira \& Nova (2021) advoga a sala de aula como um local de construção de processos coletivos de ensino-aprendizagem, onde discentes e professores se organizam num coletivo investigador e todos se envolvam com os processos coletivos de geração, regularização e sociabilização dos conhecimentos, além do desenvolvimento de competências.

Diante disso, a enfermagem fundamental, como disciplina responsável por inserir o discente na prática assistencial, assume a responsabilidade de instruir e nortear o discente na construção das competências referentes ao seu futuro como profissional. A formação inicial em enfermagem possui papel essencial na formação de competências para ação educativa do enfermeiro (Nogueira \& Cunha, 2020).

O professor possui o compromisso, enquanto no papel de educador, de instruir e guiar o discente, no momento que este é inserido no em um novo contexto educacional, o da formação profissional. É o professor que irá contribuir para o desenvolvimento de habilidades e competências voltadas para a atenção à saúde e aquelas ligadas ao processo de cuidado, além de instruir o senso de responsabilidade profissional de acordo com o perfil esperado do futuro enfermeiro.

Assim, para que o futuro profissional adquira as competências necessárias, desenvolva pensamento crítico, possua

\footnotetext{
${ }^{3}$ A entrevista qualitiva, do aluno 9, foi realizada por Daiana Moreira Gomes
}

${ }^{4}$ A entrevista qualitiva, do docente $\mathrm{D}$, foi realizada por Daiana Moreira Gomes 
conhecimento e métodos inovadores que venham contribuir na sua prática assistencial, a equipe docente deve direcionar o aprendizado durante todo o processo de formação, por meio de novos métodos de ensino e a coordenação do curso deve reestruturar a grade curricular do curso sempre que necessário, para que o discente adquira as competências necessárias para uma adaptação rápida no mercado de trabalho, que está em constante evolução e atenda as exigências dos empregadores. Durante a formação dos novos profissionais, é importante a utilização de métodos mais atualizados de ensino, que contribuam para o desenvolvimento de "pensadores" mais críticos, com maior autonomia em sua prática profissional e que consiga ainda, desenvolver a habilidade de consumir e produzir ciência.

Porém, a mudança curricular está em processo de adaptação a novos métodos, que demanda tempo de assimilação e espera, mas que segundo Ferreira \& Nascimento (2017), tem se tornado definida nos cursos de graduação de forma lenta e gradual, mesmo que, por vezes sem conseguir acompanhar os avanços tecnológicos e de comunicação, e assim contribuir para a implantação de lacunas no processo ensino-aprendizagem.

Vale destacar ainda que, os currículos devem estar preparados para as transformações digitais, uma vez que a pandemia da covid-19 trouxe um cenário diferenciado para o ensino, o que obrigou as instituições a flexibilizarem seus conteúdos e metodologias. Com isso, o ensino à distância (EAD) foi uma grande aliada para escolas e universidades que tiveram que interromper a modalidade de aula presencial e mudarem drasticamente para o ensino digital (Flauzino et al., 2021).

\section{O uso da metodologia da problematização no ensino superior}

Inovar é desafiador por mudar teórica e estruturalmente o que é tradicional, pois faz com que novas práticas sejam repensadas (Freitas et al., 2020). Por isso, o uso dessas metodologias transformadoras demanda do professor a modificação em sua didática de ensino, o que requer esforços extras aos que já é de costume, para que aos poucos deixe o tradicional de transmissão e acolhimento de informações e adote novas práticas, que melhor se adaptam as necessidades dos discentes.

Há necessidade, portanto, que para a aplicação da metodologia da problematização no ensino superior, o professor tenha preparação para trabalhar com tal método, ao se aprofundar em estudos para sua contextualização teórica, uma vez que se distingue de outras iniciativas metodológicas por possuir forte característica de fortalecer a interação social, assim como o processo de humanização durante a formação dos estudantes e profissionais da saúde, ou seja, exigir maior vínculo entre docente - discente (Menezes-Rodrigues et al., 2019).

Porém para que esse preparo dos docentes ocorra, não depende somente deles, pois faz-se necessária a evolução da instituição também. O docente A aborda que as metodologias ativas são uma vantagem, porém diz:

O que acontece é que você precisa de espaço para ela, para realizá-las, precisa de uma condição de trabalhar essas metodologias ativas. Essas metodologias precisam de tempo, de preparo, de pequenos grupos, de um ambiente apropriado. Muitas vezes não conseguimos reproduzir esse tipo de coisa, e não temos um calendário de aulas que permita que eu divida uma turma no meio para dar esse mesmo conteúdo (docente A). ${ }^{5}$

A proposta problematizadora surge com o objetivo de formar discentes cada vez mais aprimorados e com uma visão crítica da realidade e dos problemas. Na área da saúde, há uma necessidade desse pensamento crítico e criativo por ser uma área que se depara com situações de urgência e emergência, e o profissional tem que buscar estratégias adequadas para prestar a assistência e assim promover a saúde do paciente.

A metodologia da problematização busca preparar o discente da graduação para desempenhar o papel de profissional e

\footnotetext{
${ }^{5}$ A entrevista qualitiva, do docente A, foi realizada por Daiana Moreira Gomes
} 
cidadão em seu meio, porém para que isso seja possível, não basta que essa metodologia seja apenas utilizada em um só momento, por um só docente, em sua unidade curricular, pois é preciso sensibilizar mais professores para conhecê-la e aplicála, de preferência através de projetos de amplo espectro e longa duração, ao obter o tempo e as condições necessários para a aplicação dos conhecimentos e das atitudes desenvolvidas (Cortes, Padoin \& Berbel, 2018).

Alguns professores, como o docente $\mathrm{D}$, relatam que a implantação de metodologias ativas na enfermagem é necessária, pois ela aponta,

Que a metodologia ativa procede, por ser um meio de conseguir manter a atenção, a compreensão com facilidade do conteúdo programático e aí só há melhoria para o usuário, porque se você tem o conhecimento e sabe aplicá-los, quem ganha é o usuário do sistema único de saúde (docente C). ${ }^{6}$

A partir da utilização desse método de ensino, o discente 3 relata que as novas didáticas facilitam o aprendizado. Para ele a síntese do estudo se resumiu em,

\section{Mudança no meu grau de conhecimento pessoal e vontade de pesquisar e aprender sobre o assunto (discente 3$)^{7}$}

Menezes e Rodrigues et al., (2019) apontam que essa metodologia faz com que os discentes desenvolvam autonomia e independência durante a construção e consolidação do seu próprio conhecimento, o que aprimora a capacidade de buscar informação, como a aquisição de conceitos primordiais e específicos na área da saúde.

A utilização da metodologia da problematização no ensino aos discentes de enfermagem tem o papel de incentivar o discente a desenvolver sua própria opinião com um pensar crítico. A problematização proporciona ao futuro enfermeiro a capacidade de buscar extrair problemas encontrados em sua realidade, visa à resolução desse problema e consequentemente a transformação social, profissional e pessoal. Assim, a utilização do método da problematização no ensino de discentes da enfermagem fundamental mobiliza esses discentes a encontrarem problemas inseridos na realidade da disciplina, e expõe assim as verdadeiras necessidades de transformação, pois induz não só esse discente ao pensamento crítico como também faz dele o protagonista da sua própria mudança e colaborador do conhecimento desses problemas e, o leva a buscar métodos de resolução.

A problematização poderá contribuir de forma eficaz com a mudança do "modelo biomédico dominante para um modelo holístico", pois proporciona uma visão sistemática e reflexiva do cuidado. É um método que pode ajudar a transpor o modelo hospitalocêntrico, que fragmenta o cuidado com o indivíduo, para outra forma de pensar e agir, que proporciona uma ruptura com o pensamento tradicional e direciona para uma postura de inserção no contexto social em que as pessoas vivem e se relacionam, além de buscar a produção de novos conhecimentos para modificar a realidade (Cortes, Padoin \& Berbel, 2018).

A aplicação da metodologia da problematização na disciplina de fundamentos de enfermagem facilitou a ampliação do aprendizado e despertou a curiosidade da pesquisa e do saber. Alguns discentes relatam os benefícios que a aplicação da nova metodologia causou, como:

Houve sim um aumento no conhecimento, pois além de conhecer mais sobre esse problema que é atual e presente, tivemos a oportunidade de conhecer, de uma forma geral, a estrutura de aprendizado através das diretrizes (discente $8) .^{8}$

\footnotetext{
${ }^{6}$ A entrevista qualitiva, do docente C, foi realizada por Daiana Moreira Gomes

7 A entrevista qualitiva, do aluno 3, foi realizada por Daiana Moreira Gomes

${ }^{8}$ A entrevista qualitiva, do aluno 8, foi realizada por Daiana Moreira Gomes
} 
Os encontros foram esclarecedores e pude entender como funciona algumas normas na instituição. Concluo que se faz necessário que mais encontros sejam realizados com outros temas para melhor formação nossa (discente 9). ${ }^{9}$

Desta forma é de fundamental importância adquirir a problematização como "estratégia pedagógica para o educar/cuidar em Enfermagem", pois aprimora a capacidade de desenvolvimento de conhecimento científico, o que possibilita acadêmicos obterem uma formação reflexiva e mostrar a capacidade do "olhar" de enfermagem seguido de medidas críticas com proposições de modificação de uma rotina de cuidados, para estabelecer a melhor forma para uma intervenção (Sulzbacher et al., 2017).

Além disso, como ressalta Menezes-Rodrigues et al., (2019), a metodologia apresenta vantagens tais como maior comprometimento, engajamento, aumento de motivação, leitura assídua das referências indicadas e melhora da compreensão e assimilação dos conteúdos ministrados nas diferentes disciplinas, principalmente, de disciplinas profissionalizantes.

Portanto, o método da problematização possibilita o estudante a compreender as competências do enfermeiro e como podem ser utilizadas na sua educação formadora. A metodologia da problematização serviu como um método substancial para ser aplicado na unidade curricular, o que permite que o docente amplie o conteúdo e trabalhe questões ligadas à prática e ensino profissional, além de fazer esse discente aprender a aprender e desenvolver responsabilidades para um cuidado eficaz como um futuro enfermeiro.

Mediante a transformação que é necessária ocorrer no modelo educacional, vale ressaltar ainda que esse tipo de ensino inovador facilita o aprendizado remoto dos acadêmicos. Como aponta Cesário et al. (2021), a elaboração de um novo modelo de ensino por meio da Internet nas plataformas educacionais, por exemplo, favoreceu um ambiente atraente e desafiador para o discente e tornou-se uma ferramenta de ensino onde o docente consegue motivar os discentes na sala de aula, além de estimular a sua criatividade ao melhorar assim o desempenho do discente e do professor. Para ratificar esse contexto, a metodologia da problematização se apresenta como algo inovador e diferente para o discente, além de ser uma alternativa para as dificuldades do ensino de enfermagem EAD nesse contexto.

Além disso, também vale apontar que esse tipo de interação no mundo virtual que auxilia no contexto da pandemia, uma vez que os discentes de enfermagem se disponibilizam a contribuir de forma voluntária. Como salientado por Franzoi \& Cauduro (2020), a forma mais resguardada dos estudantes atuarem no combate à pandemia está pautada em ações de promoção e educação em saúde ao utilizar as mídias sociais. Tais atividades que podem ser amplamente trabalhadas pela metodologia supracitada, ou seja, além de contribuir para formação profissional da assistência, ela também serve de ferramenta de combate à covid-19 através da conscientização da população acerca de suas características e prevenção.

\section{Conclusão}

A metodologia da problematização possibilita compreender melhor as competências do enfermeiro e foi possível observar a sua aplicação na disciplina de Fundamentos de Enfermagem II em uma turma de discentes de enfermagem. Foi possível observar que essa metodologia serve como uma ferramenta significativa que possibilita ampliar o conteúdo e elaborar questões ligadas à prática e ao ensino profissional. Nota-se que, desde o início da pesquisa qualitativa, realizada em 2014, os mesmos desafios na aplicação dessa metodologia emergem de outras pesquisas da atualidade, tais como resistência dos professores, falta de preparo docente, ausência de interesse dos discentes e infraestrutura inadequada da instituição de ensino superior. O que evidencia a necessidade de continuação da aplicação e remodelação das metodologias do ensino superior. Os trabalhos mais atuais sobre o tema ressaltam a importância da desconstrução do tradicional diante das inovações na forma de

\footnotetext{
${ }^{9}$ A entrevista qualitiva, do aluno 9, foi realizada por Daiana Moreira Gomes
} 
ensinar e enfatizam, na sua essência, que isso deve ser a força motriz para a mudança do processo de ensino-aprendizagem.

Cabe ressaltar que são necessários novos estudos sobre a temática, principalmente em relação às dificuldades acerca do aprimoramento da didática dos docentes a partir da incorporação de novas metodologias. Uma maior ênfase em estratégias de ensino que envolvam ativamente o discente são temas cada vez mais urgentes em uma sociedade cada vez mais interconectada e dependente das tecnologias, um fato evidenciado após a pandemia do covid-19. No que se refere especificamente a respeito da estrutura curricular do curso de enfermagem, foi possível constatar que existe uma necessidade de aprimorar as metodologias, de forma que envolvam a formação do discente para a prática assistencial e que ensinem o futuro profissional a consumir e produzir ciência.

São grandes os desafios no ensino da enfermagem e os próximos anos exigirão cada vez mais a utilização de novas metodologias, adaptadas às transformações de um mundo moderno e cada vez mais conectado. Portanto, a elaboração de estudos que mantenham os docentes a par da necessidade da implantação de métodos de ensino inovadores é fundamental e viabiliza o aprimoramento do cuidado, forma profissionais mais capacitados, contribui para o desenvolvimento da ciência da enfermagem e permite novas experiências.

\section{Referências}

Alves, M. N. T. et al. (2017). Metodologias pedagógicas ativas na educação em saúde. Revista de Psicologia, 10(33), 339-346. https://idonline.emnuvens.com.br/id/article/view/659.

BERBEL, N. A. N. (2011). As metodologias ativas e a promoção da autonomia de estudantes. Semina: Ciências Sociais e Humanas, 32(1), 25-40 http://www.uel.br/revistas/uel/index.php/seminasoc/article/view/10326/10999.

Bordenave, J. D. \& Pereira, A. M. (2004) Estratégias de ensino-aprendizagem (25). Vozes.

Cesário, J. M. S et al. (2021). O impacto da internet das coisas (IoT) na educação digital. Revista Científica Multidisciplinar Núcleo do Conhecimento. 11(3):33-47. https://www.nucleodoconhecimento.com.br/saude/impacto-da-internet.

Cesário, J. M. S., Flauzino, V. H. P. \& Mejia, J. V. C. (2020). Metodologia científica: Principais tipos de pesquisas e suas caraterísticas. Revista Científica Multidisciplinar Núcleo do Conhecimento.05(11). 23-33. 10.32749/nucleodoconhecimento.com.br/educacao/tipos-de-pesquisas

Cortes, L. F., Padoin, S. M. D. M., \& Berbel, N. A. N. (2018). Metodologia da Problematização e Pesquisa Convergente Assistencial: proposta de práxis em pesquisa. Revista Brasileira de Enfermagem,71(2), 440-445. http://www.scielo.br/scielo.php?script=sci_arttext\&pid=S003471672018000200440 \&lng=en\&nrm=iso.

Duarte, K. A. S. et al. (2019). Importância da metodologia ativa na formação do enfermeiro: implicações no processo ensino aprendizagem. Revista Eletrônica Acervo Saúde, (36), e2022-e2022.

Duminelli, M. V. et al. (2019). Metodologias ativas e a inovação na aprendizagem no ensino superior. Brazilian Journal of Development, 5(5), $3965-3980$.

Flauzino, V. H. P et al. (2021). As dificuldades da educação digital durante a pandemia de COVID-19. Revista Científica Multidisciplinar Núcleo do Conhecimento. 11(3):5-32. https://www.nucleodoconhecimento.com.br/saude/educacao-digital.

Ferraz, R. D., Ferreira, L. G., \& Nova, C. C. C. (2021). A docência universitária e suas interfaces didáticas: movimentos de aprendizagens. Revista Diálogo Educacional, 21(68).

Franzoi, M. A. H., \& Cauduro, F. L. F. (2020). Atuação de estudantes de enfermagem na pandemia de Covid-19. Cogitare Enfermagem, 25. http:// dx.doi.org/10.5380/ce.v25i0.73491.

Freitas, F. R. N. et al. (2020). Metodologias ativas de ensino nos cursos de medicina: uma revisão integrativa. Research, Society and Development, 9(7), e151973922. https://doi.org/10.33448/rsdv9i7.3922

Fernandes, A. B., Freitas, M. C. C., \& Carneiro, S. N. V. (2019). Didática no ensino superior: possibilidades e práticas. Momento-Diálogos em Educação, 28(1), 262-277. https://periodicos.furg.br/momento/article/view/7308.

Ferreira, R. G. S, \& Nascimento, J. L. (2017). Sustentação pedagógica e legislação do ensino-aprendizagem: a formação em enfermagem no Brasil. Revista Sustinere, 5(1), 54-67. https://www.e-publicacoes.uerj.br/index.php/sustinere/article/view/25551.

Fini, M. I. (2018). Inovações no ensino Superior metodologias inovadoras de aprendizagem e suas relações com o mundo do trabalho: desafios para a transformação de uma cultura. Administração: Ensino e Pesquisa-RAEP, 19(1), 176-184.

Lei $\mathrm{n}^{\circ}$ 9394, de 20 de dezembro de 1996 (1996). Dispõe sobre as Leis de Diretrizes e Bases da Educação Nacional. www2.senado.leg.br/bdsf/bitstream/handle/id/70320/65.pdf. 
Mata, J. A. L et al. (2017). Uso da Problematização na Abordagem sobre Cultura Organizacional de Excelência para Atendimento ao Cidadão. Cadernos de pesquisas pensamento educacional. 12(30):307-319. https://seer.utp.br/index.php/a/article/view/518.

Menezes-Rodrigues, F. S et al. (2019). Vantagens da utilização do método de aprendizagem baseada em problemas (mapb) em cursos de graduação na área da saúde. Revista ibero-americana de estudos em educação. https://periodicos.fclar.unesp.br/iberoamericana/article/view/11660/8022.

Mattar, J., \& Aguiar, A. P. S. (2018). Metodologias ativas: Aprendizagem Baseada em Problemas, problematização e método do caso. Cadernos de Educação, Tecnologia e Sociedade (Brazilian Journal of Education, Technology and Society)(11: 3), 404-415.

Medeiros, R. D. C. R., Valente, G. S. C., \& Marin, F. S. (2018). Prática docente com base no currículo integrado e competências: uma revisão de literatura. Renome, 6(1), 32-44.

Miranda, A. P. (2017). Análise crítica-reflexiva na utilização da metodologia ativa. Enfermagem Brasil, 16(3), $182-189$.

Nogueira, V., \& Cunha, I. C. K. O. (2020). Competências de ensino em enfermagem: uma revisão narrativa. International Journal of Health Management Review, 6(2).

Oliveira, P. R., Pereira, S. A., \& Castro, O. (2018). Curso de graduação em enfermagem sob a ótica do acadêmico. Indagatio Didactica, 10(2), $283-296$.

Penof, D. G., Leonardo, S. B., \& Farina, M. C. (2020). Desafios da interdisciplinaridade no ensino superior: o papel do coordenador de curso nos" Projetos e Atividades Especiais-PAES". Administração: Ensino e Pesquisa, 21(1), 24-51.

Rios, D. R. D. S. \& Caputo, M. C. (2019). Para além da formação tradicional em saúde: experiência de Educação Popular em Saúde na formação médica. Revista Brasileira de Educação Médica,43(3), 184-195. http://www.scielo.br/scielo.php?script=sci_arttext\&pid=S01005502201 9000300184\&lng=en\&nrm=iso.

Silva, G. D. S. S. et al. (2020). Metodologia da problematização na integração entre vigilância epidemiológica e a assistência: relato de ações extensionistas. Enfermagem em Foco, 11(5).

Sulzbacher, M. M et al. (2017). Metodologia da problematização como estratégia de ensino e aprendizagem na enfermagem. Revista Enfermagem Atual In Derme, 80(18). https://revistaenfermagematual.com.br/index.php/revista/article/view/349. 